\title{
Proportional Venn diagram and determinants of allergic respiratory diseases in Italian adolescents
}

Cibella F, Cuttitta G, La Grutta S, Melis MR, Lospalluti ML, Uasuf CG, Bucchieri S, Viegi G. Proportional Venn diagram and determinants of allergic respiratory diseases in Italian adolescents.

Pediatr Allergy Immunol 2010.

(C) 2010 John Wiley \& Sons A/S

Large variations in prevalence of atopy and allergic diseases are reported worldwide in children, but in epidemiological studies the use of skin prick tests (SPT) and spirometry along with questionnaires is not common in the Mediterranean Area. The present work was aimed at evaluating the prevalence of current asthma (CA), rhinoconjunctivitis $(\mathrm{RC})$, and eczema (E), with atopy and respiratory function, and the role of risk factors for allergic respiratory diseases. A total of 2150 Italian schoolchildren were cross-sectionally investigated through respiratory questionnaire, SPT, and spirometry. A proportional Venn diagram quantified the distribution of $\mathrm{CA}, \mathrm{RC}$, and $\mathrm{E}$, stratifying for allergic sensitization to show differences in prevalence of allergic diseases among subjects with and without positive SPT. CA prevalence was $4.2 \%, \mathrm{RC} 17.9 \%$, and $\mathrm{E} 5.3 \%$. CA and RC increased, while $\mathrm{E}$ decreased, with respect to previous local studies. Allergic sensitization prevalence (evaluated as positive response to at least one SPT) was $39.2 \%$. A double Venn diagram identified 15 categories. Atopic CA was threefold more frequent than non-atopic CA. Atopic vs non-atopic RC and $\mathrm{E}$ were $9.6 \%$ vs $10.3 \%$ and $2.0 \%$ vs $3.3 \%$, respectively. Atopic vs non-atopic RC associated with CA were $1.6 \%$ vs $0.5 \%$; the same figures for RC associated with $\mathrm{E}$ were $0.8 \%$ vs $1.3 \%$. Asymptomatic atopic subjects were $27.0 \%$. Atopy, RC, parental asthma, and environmental risk factors were associated with CA. Atopy and environmental factors were risk factors also for RC. Asthma and traffic exposure were linked to reduced lung function. Respiratory allergic diseases are still increasing and largely concomitant in Italian adolescents. Atopy is more important for CA than RC. Avoiding exposures to measured environmental risk factors would prevent $41 \%$ of current asthma and $34 \%$ of rhinoconjunctivitis.

\author{
Fabio Cibella ${ }^{1}$, Giuseppina Cuttitta ${ }^{1}$, \\ Stefania La Grutta ${ }^{2}$, Mario R. Melis ${ }^{1}$, \\ Maria L. Lospalluti ${ }^{1}$, Carina G. Uasuf ${ }^{1}$, \\ Salvatore Bucchieri ${ }^{1}$ and \\ Giovanni Viegi ${ }^{1}$ \\ ${ }^{1}$ Consiglio Nazionale delle Ricerche, Istituto di \\ Biomedicina e Immunologia Molecolare, Palermo, \\ Italy, ${ }^{2}$ Health and Environment Unit, Regional Agency \\ for Environment Protection - ARPA-Sicilia, Palermo,
} Italy

Key words: epidemiology of asthma; childhood allergy; skin tests; questionnaire; spirometry

Fabio Cibella, Consiglio Nazionale delle Ricerche, Istituto di Biomedicina e Immunologia Molecolare, via U. La Malfa, 153 - 90146 Palermo, Italy E-mail: cibella@ibim.cnr.it

Accepted 6 August 2010
Large variations in the prevalence of allergic sensitization and symptoms of asthma (2.8$32.6 \%$ ) (1) and rhinoconjunctivitis (3.9-45.1\%) (2) have been reported in children and adolescents worldwide. In Italy, a trend toward a stabilization of asthma prevalence (as lifetime asthma) has been recently observed in adolescents in the period 1994-2002 $(3,4)$, while a 40-49\% prevalence of subjects positive to skin prick testing has been found $(5,6)$. Both host susceptibility and environmental factors seem to contribute to these changes (1-6).

Indeed, it is difficult to compare the prevalence rates among surveys because of differences in study populations, diagnostic criteria, environmental and host risk factors, and methodological approach. As regards the latter, only the questionnaire without pulmonary function testing is 
commonly applied. Also skin prick tests are uncommonly used, even though skin prick testing improves the classification of allergic diseases based on a structured allergy history alone (7). In the last 5 years, few studies were performed in the Mediterranean Area including questionnaire, pulmonary function testing, and skin prick tests (8).

The use of a Venn diagram, seldom used after the ISAAC 1998 report (12), may offer a more realistic information on the prevalence of allergic diseases by simultaneously quantifying the frequencies of different coexistent allergic diseases.

Thus, aims of this study were (i) to carry out an epidemiological survey investigating a large sample of adolescents of the Mediterranean area through questionnaire, spirometry, and skin prick test to quantify the proportion of prevalence of asthma, $\mathrm{RC}$, and eczema (E), in association with allergic sensitization and respiratory function, and (ii) to evaluate the role of environmental and host risk factors for allergic respiratory diseases and to estimate the reduction in their burden obtainable through the abatement of avoidable environmental exposures.

\section{Materials and methods}

Study design

This cross-sectional study was conducted in a random sample of adolescents, aged 10-17 yr, living in the city of Palermo, Mediterranean area of Southern Italy (November 2005-May 2006). In the whole city, there were 59 junior high schools with 27,813 students. After subdividing the municipality in three geographical zones (coastal, downtown, and hilly), 16 schools with 9922 children were selected. From them, 2481 children were randomly selected (one every four). Three hundred and three adolescents did not obtain parental consent or were not present at school on the day of the study. The response rate was $87.8 \%$ : 2178 students completed a questionnaire based on SIDRIA Study, the Italian section of $\operatorname{ISAAC}(3,8)$ and underwent lung function tests and skin prick tests (SPT) at school. Twenty-eight children refused SPT and/or were not able to perform a valid spirometry, leaving 2150 children $(86.7 \%$ of the 2481 subjects of the random sample), mean age $12.6 \mathrm{yr}$ ( \pm 1.0 s.d.), with a complete evaluation. The study was approved by the Institutional Ethical Committee. All parents of the invited adolescents signed a written informed consent. According to the Italian law, the respect of individual privacy concerning clinical data was granted.

\section{Questionnaire}

The SIDRIA self-administered questionnaire was completed by adolescents at school, regarding past and current respiratory allergic symptoms and personal information (smoke and other environmental exposures) (3). The three core questionnaire modules of ISAAC for 13- to 14yr-olds (wheezing, rhinitis, and eczema) (9) were used: questionnaires were included in the analyses only if all the three core sections were completed.

Child's history of 'asthma ever' was defined as a positive answer to the question 'Have you ever had asthma?'. Rhinoconjunctivitis was defined as a positive answer to both the questions 'Have you ever had a problem with sneezing, or runny, or blocked nose apart from common cold or flu in the last 12 months?' and 'In the past 12 months, has this nose problem been accompanied by itching and/or watering eyes?' (9). Based on these criteria, we identified three subgroups: subjects with asthma ever (A), regardless of the presence of rhinoconjunctivitis; subjects with rhinoconjunctivitis (RC); and children without asthma or rhinoconjunctivitis (nAnRC). Moreover, current asthma (CA) was defined as asthma ever plus at least a wheeze episode in the last 12 months. Eczema (E) was defined as positive answers to both the following questions: 'In the last 12 months, have you had an itchy rush which was coming and going for at least 6 months?' and 'Has this itchy rush at any time affected any of the following places: folds of elbows, behind the knees, in front of the ankles, under the buttocks, or around the neck, ears, or eyes?'. Information on possible confounders or effect modifiers were also collected. Mold/dampness exposure was evaluated using the question: 'Have you ever seen mold/dampness/fungi on the walls or on the ceiling of your bedroom?'. In children, current passive smoking exposure (ETS) was assessed through the question 'Are there smokers at home?'. Self-reported traffic exposure was recorded as the frequency of trucks passing on the street of residence on weekdays (never/rare/frequent/constant), and subjects were considered exposed if they answered 'frequent' or 'constant'.

Family history in parents for asthma was defined as at least one parent with personal history of asthma.

\section{Skin prick tests}

Skin prick tests were performed according to EAACI recommendations (10) with a standard 
panel including dermatophagoides mix, grass mix, parietaria judaica, olive, dog and cat dander, alternaria, and blattella germanica, plus a positive (histamine $1 \%$ ) and a negative (saline) control (Stallergènes Italia S.r.1., Milan, Italy). The reading was performed after $15 \mathrm{~min}$ : reactions were considered positive if the mean wheal diameter (computed as the maximum diameter plus its orthogonal divided by two) was $3 \mathrm{~mm}$ or greater, after having subtracted the wheal diameter of the reaction to the negative control. Allergic sensitization was defined as the presence of at least one positive skin prick test. Atopic index (AI) was computed as the number of individual positive skin prick tests and classified as follows: 0-non-atopic, 1-one positive skin test, 2-two positive skin tests, 3-three or more positive skin tests. Allergens were grouped in outdoor (grass mix, parietaria judaica, olive), indoor (dermatophagoides, dog and cat dander, and blattella germanica) allergens, and mold (alternaria).

\section{Spirometry}

Height (in $\mathrm{cm}$ ) and weight (in $\mathrm{kg}$ ) were measured in all the children in standing position without shoes, using a stadiometer and an electronic digital scale. Pulmonary function tests were performed through a portable spirometer (MicroLoop, Micro Medical, Chatham Maritime, Kent, UK). Forced expiratory volume in onesecond $\left(\mathrm{FEV}_{1}\right)$, forced vital capacity $(\mathrm{FVC})$, and maximum midexpiratory flow $\left(\mathrm{FEF}_{25-75 \%}\right)$ were measured according to ATS/ERS guidelines (11): the best $\mathrm{FVC}$ and $\mathrm{FEV}_{1}$ were retained, and $\mathrm{FEF}_{25-75 \%}$ was selected from the manoeuvre with the largest sum of FEV 1 and FVC. Spirometric predicted values were those from Pistelli et al. (12). An impaired pulmonary function was defined when $\mathrm{FEV}_{1} / \mathrm{FVC}^{2} \%$ was below the 5th percentile of its normal distribution (below $87 \%$ of predicted for boys and below $90 \%$ for girls) (12).

\section{Data analyses}

A double proportional Venn diagram, following Viegi et al. (13), was used to describe the distribution of $\mathrm{CA}, \mathrm{RC}$, and $\mathrm{E}$ among subjects, and their association, according to the presence of atopy. Parametric (chi-square test and one-way analysis of variance - ANOVA) and non-parametric statistical tests (Kruskal-Wallis) were performed. To study the independent variables able to influence the risk for a dependent variable, logistic regression models were used, and odds ratios (OR) with corresponding 95\% confidence intervals (CI) were calculated for all predictors. The population attributable risk (PAR\%) was computed to estimate the amount of asthma (as both A and CA) and rhinoconjunctivitis because of atopy and other variables, which might be prevented by eliminating the exposure to the specific risk factor, following the equation: PAR $=\left[\mathrm{N}_{1}\left(\mathrm{R}_{1}-\mathrm{R}_{0}\right)\right] /\left(\mathrm{N}_{1} \mathrm{R}_{1}+\mathrm{N}_{0} \mathrm{R}_{0}\right)=$ $[p(R R-1)] /[p(R R-1)+1]$ where $\mathrm{p}$ is the proportion of population exposed and $R R$ is the adjusted estimate of relative risk of the exposed vs the unexposed (14).

All computations were performed by StatView statistical software package (SAS Institute, Cary, NC, USA). A probability level of $\mathrm{p}<0.05$ was selected as statistically significant.

\section{Results}

Prevalence rates

Sample characteristics (2150 subjects: $\mathrm{M}=1057$, $49.2 \%$ ) are shown in Table 1. Except for asthma, no chronic pulmonary diseases were reported; none of the children declared to be an active smoker. Prevalence of allergic sensitization was $39.2 \%(45.0 \%$ in boys and $33.5 \%$ in girls, $\left.\mathrm{p}<0.0001, \chi^{2}\right)$. About one of two students was exposed to ETS and over one of five reported a relevant exposure to traffic in the zone of residence.

In the overall sample, prevalence rates of CA, $\mathrm{RC}$, and $\mathrm{E}$ were $4.2 \%, 17.9 \%$, and $5.3 \%$, respectively: they are described as double proportional Venn diagram (8), separately for

Table 1. General characteristics of the sample

\begin{tabular}{lcc}
\hline & Males & Females \\
\hline Gender (No., \%) & $1057(49.2)$ & $1093(50.8)$ \\
Age (mean \pm s.d.) & $12.60( \pm 1.05)$ & $12.59( \pm 1.03)$ \\
Height, $\mathrm{cm}$ (mean \pm s.d.) & $154.9( \pm 9.4)$ & $153.5( \pm 7.2)$ \\
Weight, $\mathrm{kg}$ (mean \pm s.d.) & $51.9( \pm 13.7)$ & $50.1( \pm 12.3)$ \\
$\mathrm{BMI}, \mathrm{kg} / \mathrm{m}^{2}$ (mean \pm s.d.) & $21.4( \pm 4.4)$ & $21.1( \pm 4.3)$ \\
Subjects with at least one positive SPT & $476(45.0)$ & $366(33.5)^{*}$ \\
(No., \%) & & \\
Exposure to environmental tobacco smoke & $589(55.7)$ & $627(57.4)$ \\
(No., \%) & & \\
Exposure to traffic in the zone of residence & & \\
$\quad$ Rare (No., \%) & $586(55.4)$ & $619(56.6)$ \\
Frequent (No., \%) & $150(14.2)$ & $175(16.0)$ \\
Constant (No., \%) & $61(5.8)$ & $67(6.1)$ \\
Mold/dampness exposure ${ }^{\dagger}$ (No., \%) & $147(13.9)$ & $175(16.0)$ \\
\hline & \\
&
\end{tabular}


subjects with and without allergic sensitization (Fig. 1). Fifteen categories were identified through the Venn diagram: allergic CA (3.1\%) was almost threefold more frequent than nonallergic CA (1.1\%). Conversely, allergic vs nonallergic $\mathrm{RC}$ and $\mathrm{E}$ were $9.6 \%$ vs $10.3 \%$ and $2.0 \%$ vs $3.3 \%$, respectively. Allergic vs non-allergic RC associated with CA were $1.6 \%$ vs $0.5 \%$; the same figures for $\mathrm{RC}$ associated with $\mathrm{E}$ were $0.8 \%$ vs $1.3 \%$. Asymptomatic subjects with allergic sensitization were $27.0 \%$.

Overall RC prevalence was $20.0 \%$ (17.9\% alone and $2.1 \%$ in association with CA). Indeed, when considering only individuals with CA $(4.2 \%$ of the total), one half of them had also RC. Prevalence rates of wheeze ever, wheeze in the last 12 months, and $A$ were $21.7 \%, 10.5 \%$, and $12.0 \%$, respectively. Subjects without symptoms were $77.9 \%$. No significant difference in gender distribution was found for asthma and wheeze. RC was $21.0 \%$ among girls and $14.7 \%$ among boys $\left(\mathrm{p}=0.0001, \chi^{2}\right)$; similarly, E was $6.3 \%$ among girls and $4.2 \%$ among boys $\left(p=0.026, \chi^{2}\right)$.

\section{Allergic sensitization and respiratory function data}

Gender, prevalence of allergic sensitization, and respiratory function data for $\mathrm{CA}, \mathrm{RC}$, and nAnRC in the total sample are described in Table 2. Allergic sensitization was more frequent among CA $(73.3 \%)$ than $\mathrm{RC}(44.6 \%)$ and nAnRC $\left(36.0 \%, \mathrm{p}<0.0001, \chi^{2}\right)$.

There were $17.3 \%$ subjects with one, $10.1 \%$ with two, and $11.8 \%$ with three or more positive SPT, while subjects without allergic sensitization were $60.8 \%$. With increasing AI (Fig. 2 panel a), the proportion of CA increased from $1.8 \%$ to $10.3 \%\left(\mathrm{p}<0.0001, \chi^{2}\right)$; also, the proportion of RC significantly changed (from $16.3 \%$ to $24.9 \%$, $\left.\mathrm{p}=0.005, \chi^{2}\right)$. Among 581 asymptomatic subjects with allergic sensitization, an $\mathrm{AI}=1$ (i.e., monosensitization) was significantly more frequent than among allergic symptomatics $(46.5 \%$ vs $38.6 \%)$, while $\mathrm{AI}=3$ was less frequent $(27.6 \%$ vs $\left.35.9 \%, p=0.035, \chi^{2}\right)$. Significant increases in the proportion of CA were also found as an effect of sensitization to indoor $\left(\mathrm{p}<0.0001, \chi^{2}\right)$ and outdoor allergens ( $\mathrm{p}<0.0001, \chi^{2}$, Fig. 2, panel $b$ and $\mathrm{c}$, respectively). No significant increase of CA was found for sensitization to mold ( $\mathrm{p}=0.057$, $\chi^{2}$, Fig. 2, panel d).

Sensitization to dermatophagoides was the most represented, followed by parietaria pollen: among 842 subjects with positive SPT, $59.6 \%$ were sensitized to dermatophagoides $(18.6 \%$ monosensitized) and $37.1 \%$ to parietaria $(7.6 \%$ monosensitized). Prevalence of CA was higher among subjects monosensitized to dermatophagoides $(9.0 \%)$ with respect to the remaining subjects $\left(3.8 \%, \mathrm{p}=0.002, \chi^{2}\right)$, while no significant difference was found for subjects monosensitized to parietaria. Prevalence of RC among subjects monosensitized to dermatophagoides or parietaria was not significantly different from those in the whole sample.

Lung function indices, as percent of predicted, were (mean \pm s.d.): FVC $92.9 \pm 12.6 \%$, FEV $_{1}$ $92.2 \pm 11.8 \%, \mathrm{FEV}_{1} / \mathrm{FVC} 99.8 \pm 6.6 \%$, and $\mathrm{FEF}_{25-75 \%} 85.8 \pm 19.2 \%$ among boys; FVC $91.5 \pm 10.9 \%, \quad \mathrm{FEV}_{1} \quad 88.6 \pm 10.8 \%, \quad \mathrm{FEV}_{1} /$

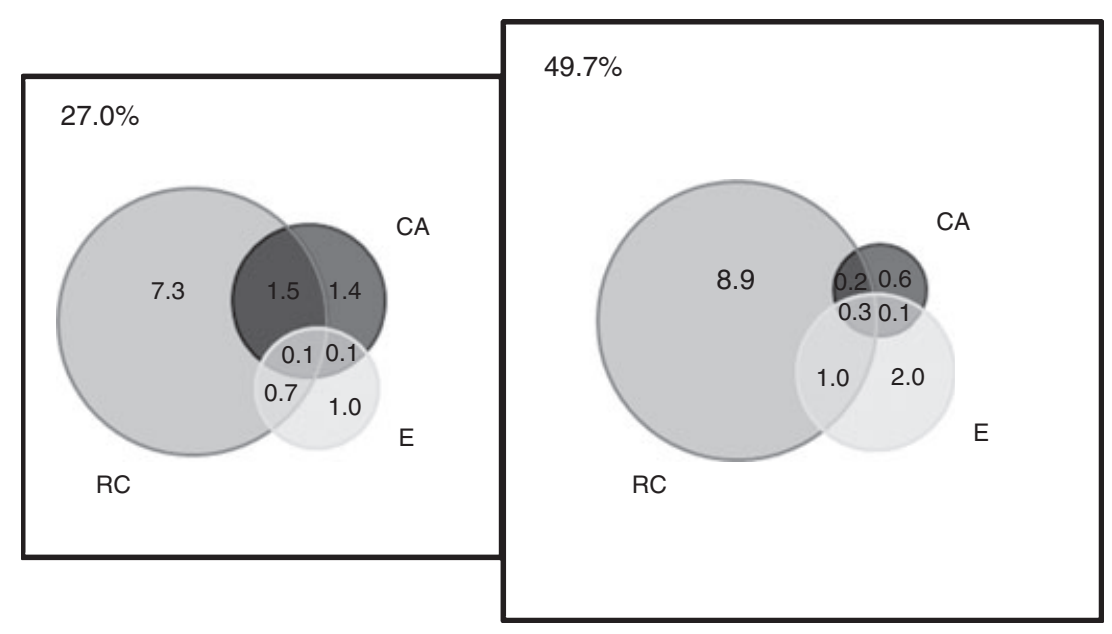

Fig. 1. Proportional double Venn diagram. A proportional double Venn diagram has been used to quantify the distribution in the whole population sample of current asthma (CA), rhinoconjunctivitis (RC), and eczema (E) separately for the 842 subjects with (on the left) and the 1308 subjects without (on the right) positive skin prick test. Each prevalence value is referred to the whole investigated population sample. The prevalence of asymptomatic subjects with positive skin prick test $(27 \%)$ and that of asymptomatic subjects with negative skin prick test $(49.7 \%)$ is indicated. 
Proportional Venn diagram and determinants of allergic respiratory diseases

Table 2. Distribution of gender, allergic sensitization, and respiratory function data for each subgroup of current asthma, rhinoconjunctivitis, and non-asthmatic nonrhinitic subjects

\begin{tabular}{|c|c|c|c|c|}
\hline & $\begin{array}{l}\text { Total sample } \\
(\mathrm{N}=2150)\end{array}$ & $\mathrm{CA}(\mathrm{N}=90)$ & $\mathrm{RC}(\mathrm{N}=385)$ & $\mathrm{nAnRC}(\mathrm{N}=1675)$ \\
\hline Gender (M/F) & $1057 / 1093$ & $50 / 40$ & $155 / 230$ & $852 / 823$ \\
\hline Subjects with pos. SPT (No, \%) & $839(39.2)$ & $66(73.3)^{*}$ & $171(44.6)$ & $602(36.0)$ \\
\hline No. of sensitizations (median and IO range) & $0(0-1)$ & $1(0-3)^{* *}$ & $0(0-2)$ & $0(0-1)$ \\
\hline Sensitized to dermatoph. (No, \%) & $500(23.3)$ & $44(48.9)^{*}$ & $113(29.5)$ & $343(20.5)$ \\
\hline Sensitized to parietaria (№, \%) & $311(14.5)$ & $30(33.3)^{*}$ & 70 (18.3) & $211(12.6)$ \\
\hline $\mathrm{FEV}_{1}(\%$ pred, mean \pm s.d.) & $90.3(11.4)$ & $87.5( \pm 11.6)^{\#}$ & $89.9( \pm 11.4)$ & $90.6( \pm 11.4)$ \\
\hline FVC (\% pred, mean \pm s.d.) & $92.2(11.8)$ & $91.4( \pm 12.3)$ & $92.1( \pm 11.5)$ & $92.3( \pm 11.8)$ \\
\hline $\mathrm{FEV}_{1} / \mathrm{FVC} \%$ (\% pred, mean \pm s.d.) & $100.5(6.5)$ & $97.6( \pm 7.5)^{\# \#}$ & $100.6( \pm 6.7)$ & $100.6( \pm 6.4)$ \\
\hline $\mathrm{FEF}_{25-75 \%}(\%$ pred, mean \pm s.d. $)$ & $84.8(19.1)$ & $76.0( \pm 18.3)^{\S}$ & $84.7( \pm 19.5)$ & $85.2( \pm 19.0)$ \\
\hline Impaired lung function (No, \%) & $90(4.3)$ & $10(11.2)^{\S \S}$ & $18(4.7)$ & $62(3.8)$ \\
\hline
\end{tabular}

CA: current asthma; RC: Rhinoconjunctivitis; nAnRC: non-asthmatic non-rhinitic; SPT: skin prick tests; IQ range: interquartile range.

${ }^{*} p<0.0001\left(\chi^{2}\right)$.

$* * p<0.0001$ (Kruskal-Wallis).

${ }^{\#} \mathrm{p}=0.012$ with $\mathrm{nAnRC}$ (one-way anova).

$\#$ \# $<0.0001$ with both RC and nAnRC (one-way anova).

$\S_{\mathrm{p}}=0.0004$ with $\mathrm{RC}, \mathrm{p}<0.0001$ with nAnRC (one-way anova).

$\S \S_{p}=0.003\left(\chi^{2}\right)$.
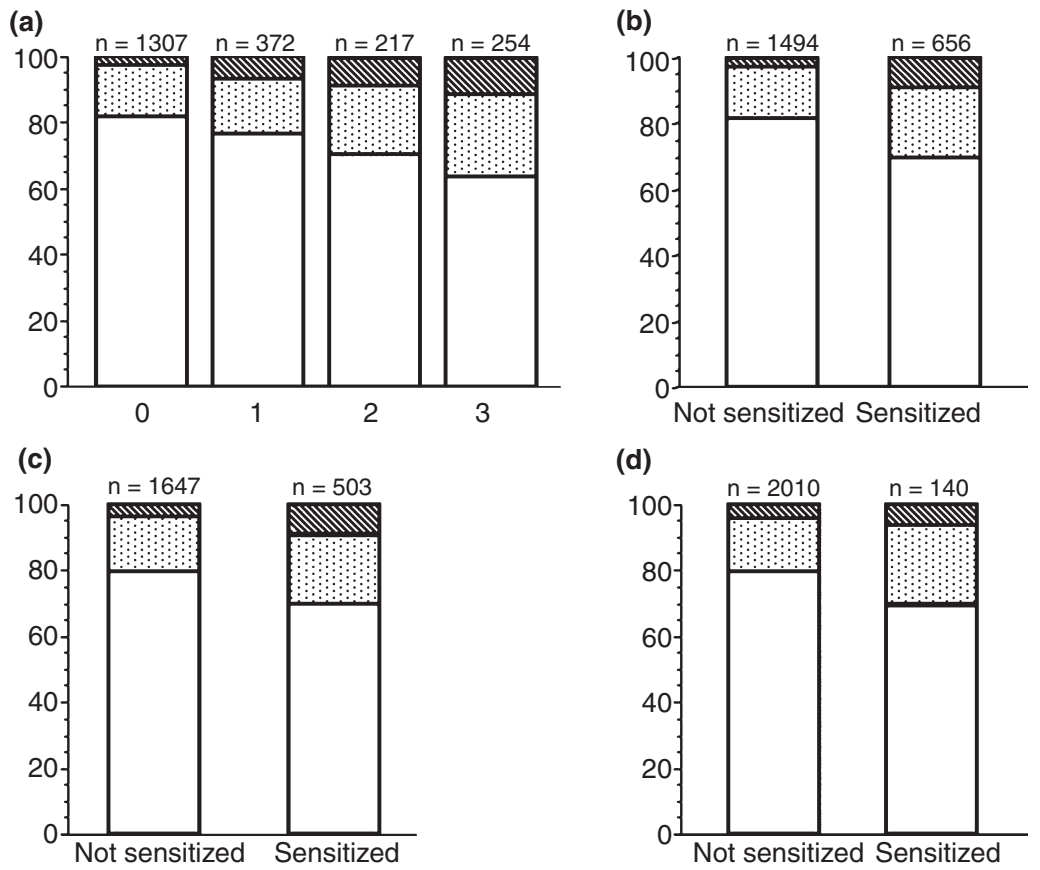

Fig. 2. Asthma and rhinoconjunctivitis distribution in different classes of atopic sensitization. Panel a: Distribution of children with current asthma, with rhinoconjunctivitis, and without current asthma/rhinoconjunctivitis, as percentages within each class of atopic index. Class 0: non-atopic; class 1: one positive skin reaction; class 2: two positive skin reactions; and class 3: three or more positive skin reactions. The absolute number of subjects in each subclass is shown. $\mathrm{p}$ for trend $<0.0001$ current asthma and $\mathrm{p}=0.005$ for rhinoconjunctivitis $\left(\chi^{2}\right)$. Panels $\mathrm{b}-\mathrm{d}$ : Differences in distribution of children with current asthma, with rhinoconjunctivitis, and without current asthma/rhinoconjunctivitis because of sensitization to indoor allergens $\left(p<0.0001, \chi^{2}\right.$, panel B), outdoor allergens $\left(p<0.0001, \chi^{2}\right.$, panel C), and molds $\left(p=0.057, \chi^{2}\right.$, panel D).

FVC $100.1 \pm 6.3 \%$, and $\mathrm{FEF}_{25-75 \%} 83.8 \pm 19.0 \%$ among girls.

Asthmatics had significantly lower $\mathrm{FEV}_{1} /$ $\mathrm{FVC} \%$ and $\mathrm{FEF}_{25-75 \%}$ (\% predicted) with respect to $\mathrm{nAnRC}$ and $\mathrm{RC}$ subjects, while $\mathrm{FEV}_{1}$ was significantly lower in CA with respect to $\mathrm{nAnRC}$.
An impaired lung function was found in $4.3 \%$ of the whole sample vs $11.2 \%$ of subjects with CA $\left(\mathrm{p}=0.0009, \chi^{2}\right)$. Among subjects without CA (i.e., $\mathrm{RC}+\mathrm{nAnRC}$ ), $6.1 \%$ of those reporting exposure to traffic had impaired lung function with respect to $3.4 \%$ of those not exposed. 
Table 3. Multiple logistic regression analysis for current asthma, rhinoconjunctivitis not associated with asthma, and impaired lung function

\begin{tabular}{|c|c|c|c|c|c|c|c|c|}
\hline & \multicolumn{2}{|c|}{ Current asthma } & \multicolumn{2}{|c|}{ Rhinoconjunctivitis } & \multicolumn{2}{|c|}{ Impaired lung function } & \multicolumn{2}{|c|}{ Eczema } \\
\hline & OR & $95 \% \mathrm{Cl}$ & OR & $95 \% \mathrm{Cl}$ & $\mathrm{OR}$ & $95 \% \mathrm{Cl}$ & $\mathrm{OR}$ & $95 \% \mathrm{Cl}$ \\
\hline Gender (female vs male) & 0.74 & $0.47-1.17$ & 1.51 & $1.21-1.89$ & 1.62 & $1.04-2.52$ & 1.43 & $0.96-2.12$ \\
\hline ETS & 1.41 & $0.88-2.25$ & 1.43 & $1.14-1.79$ & 0.68 & $0.44-1.04$ & 1.05 & $0.70-1.55$ \\
\hline Mold/dampness & 1.57 & $0.91-2.70$ & 1.51 & $1.14-2.01$ & 0.95 & $0.52-1.71$ & 1.19 & $0.73-1.94$ \\
\hline Exposure to traffic & 1.84 & $1.14-2.95$ & 1.39 & $1.08-1.79$ & 1.78 & $1.12-2.83$ & 1.19 & $0.76-1.85$ \\
\hline Current asthma & - & - & 3.14 & $1.98-4.99$ & 3.13 & $1.46-6.73$ & 2.80 & $1.42-5.53$ \\
\hline Rhinoconjunctivitis & 3.28 & $2.08-5.18$ & - & - & 1.00 & $0.59-1.70$ & 2.56 & $1.69-3.86$ \\
\hline Eczema & 3.20 & $1.62-6.32$ & 2.57 & $1.71-3.88$ & 1.02 & $0.42-2.47$ & - & - \\
\hline Parental asthma & 5.54 & $3.34-9.17$ & 1.15 & $0.80-1.66$ & 0.81 & $0.39-1.69$ & 0.93 & $0.49-1.77$ \\
\hline Atopic index 1 & $3.33^{*}$ & $1.81-6.10$ & $1.13^{*}$ & $0.84-1.54$ & 0.75 & $0.39-1.43$ & 1.06 & $0.64-1.74$ \\
\hline Atopic index 2 & $4.16^{*}$ & $2.12-8.18$ & $1.73^{*}$ & $1.22-2.46$ & 0.92 & $0.44-1.93$ & 0.41 & $0.17-0.98$ \\
\hline Atopic index 3 & $5.05^{*}$ & $2.75-9.28$ & $2.07^{*}$ & $1.50-2.85$ & 1.32 & $0.71-2.44$ & 0.72 & $0.38-1.37$ \\
\hline
\end{tabular}

Data are expressed as odds ratio (OR) and 95\% confidence interval (95\%CI). ETS: current passive smoking exposure.

Atopic index: 0-non-atopic, 1-one positive skin test, 2-two positive skin tests, and 3-three or more positive skin tests.

${ }^{*} p$ for trend for Atopic index: $<0.0001$.

Risk factors associated with allergic sensitization and respiratory diseases

Self-reported traffic exposure was a significant risk factor for allergic sensitization (OR 1.29, CI 1.04-1.60) when corrected for gender, mold/ dampness, ETS, and parental history for allergic diseases in a logistic model. In particular, the association was found for individual sensitized to indoor allergens (OR 1.30, CI 1.04-1.63).

Self-reported traffic exposure, RC, E, parental asthma, and AI were significant risk factors for CA (Table 3). In a different logistic model, significant risk factors for RC were female gender, ETS, mold/dampness exposure, traffic exposure, CA, E, and the highest AI classes, while female gender, $\mathrm{CA}$, and exposure to traffic were significant predictors of impaired lung function (Table 3 ).

In Table 4, PAR \% for CA, RC, impaired lung function, and $\mathrm{E}$ are reported. Allergic sensitization, RC, and parental asthma accounted for the largest attributable fractions for CA. Avoidable environmental factors (exposures to mold/dampness, ETS, and traffic) were responsible of $40.8 \%$ CA cases. For RC, allergic sensitization and CA had lower influence $(17.2 \%$ and $8.6 \%$, respectively), while the cumulative attributable risk because of avoidable environmental factors was $33.6 \%$. Sensitization to dermatophagoides was responsible of $6.7 \%$ of PAR for RC. At last, CA and traffic accounted for $8.5 \%$ and $14.1 \%$ of impaired lung function, respectively.

In Table 5, PAR \% for CA and RC attributable to each individual allergen are reported. The most important contribution to $\mathrm{PAR} \%$ from an
Table 4. Population attributable risk, expressed as percent (PAR\%), for different variables and relevant to current asthma, rhinoconjunctivitis not associated with asthma, and impaired lung function $\left(\mathrm{FEV}_{1} / \mathrm{FVC} \%\right.$ below the 5th percentile of its normal distribution)

\begin{tabular}{|c|c|c|c|c|}
\hline & $\begin{array}{l}\text { Current } \\
\text { asthma }\end{array}$ & Rhinoconjunctivitis & $\begin{array}{l}\text { Impaired } \\
\text { lung } \\
\text { function }\end{array}$ & Eczema \\
\hline Atopy & 54.5 & 17.2 & - & - \\
\hline Parental asthma & 29.8 & - & - & - \\
\hline Current asthma & NA & 8.6 & 8.5 & 6.7 \\
\hline Rhinoconjunctivitis & 32.2 & NA & - & 23.1 \\
\hline Eczema & 10.1 & 7.4 & - & NA \\
\hline $\begin{array}{l}\text { Environmental } \\
\text { tobacco smoke }\end{array}$ & 18.1 & 18.8 & - & - \\
\hline $\begin{array}{l}\text { Mold/dampness } \\
\text { exposure }\end{array}$ & 7.6 & 7.0 & - & - \\
\hline Exposure to traffic & 15.1 & 7.8 & 14.1 & - \\
\hline
\end{tabular}

Missing PAR values were not computed because of very low ORs in the relevant logistic models.

NA, value not available.

Table 5. Population attributable risk, expressed as percent (PAR\%), for sensitization to different allergens and relevant to current asthma and rhinoconjunctivitis not associated with asthma

\begin{tabular}{lcc}
\hline & Current asthma & Rhinoconjunctivitis \\
\hline Dermatophagoides mix & 19.8 & 8.9 \\
Parietaria judaica & 5.4 & 3.0 \\
Olive & 6.1 & 5.0 \\
Dog dander & 5.3 & 1.4 \\
Cat dander & 7.2 & 1.0 \\
Alternaria & - & 1.3 \\
\hline
\end{tabular}

No PAR calculation was possible for Grass mix and Blattella germanica because of their low and not significant ORs in the logistic regression model.

individual allergen came from sensitization to dermatophagoides for both CA and RC (19.8\% and $8.9 \%$, respectively). 
Determinants of eczema

Distribution of $\mathrm{E}$ was significantly different among male and female subjects $(4.2 \%$ and $6.3 \%$, respectively, $\mathrm{p}=0.026, \chi^{2}$ ). In a logistic model, when corrected for gender, environmental factors, and family history for atopic diseases, only CA (OR 2.80, CI 1.42-5.53) and RC (OR 2.56, CI 1.69-3.86) were significant risk factors for $\mathrm{E}$, while female gender was close to the level of significance (OR 1.43, CI 0.96-2.12, Table 3). $\mathrm{RC}$ and $\mathrm{CA}$ accounted for $23.1 \%$ and $6.7 \%$ of $\mathrm{E}$, respectively (Table 4).

\section{Discussion}

We found an elevated prevalence of allergic sensitization among adolescents, with an increased risk for CA associated with the increasing number of individual positive SPT. Sensitization to dermatophagoides was associated with increased prevalence of $\mathrm{CA}$ also in monosensitized individuals. Environmental factors appeared to be relevant for allergic sensitization, CA, and $\mathrm{RC}$. The latter was only in part linked to atopy in our sample. Conversely, only $\mathrm{CA}$ and $\mathrm{RC}$, and not environmental factors, were associated with E.

\section{Respiratory symptoms}

Our prevalence rates of respiratory symptoms rank intermediate with respect to worldwide prevalence values $(1,2)$. Because our classification of $\mathrm{A}, \mathrm{CA}, \mathrm{RC}$, and $\mathrm{E}$ followed the definition of previous Italian epidemiological studies $(3,4)$, we could perform a meaningful comparison with earlier evaluations. A and CA prevalence rates are higher than in the Southern Italian part of the SIDRIA2 Study $(12.0 \%$ vs $9.7 \%$ and $4.2 \%$ vs $3.7 \%$, respectively) (4). Our data are close to those found in 2002 in Italian metropolitan areas (lifetime asthma $12.6 \%$, current asthma 5.4\%) (3). RC prevalence was $20.0 \%$ ( $17.9 \%$ as single condition and $2.1 \%$ in association with CA), slightly lower than in Italian metropolitan areas $(21.1 \%)$ (3), but higher than in the Southern Italian part of the SIDRIA2 Study (17.9\%) (4).

Wheezing in the last 12 months $(6.2 \%)$ and lifetime asthma (9.3\%) found in Palermo in 2002 (data on file, SIDRIA2 Study) (4) were lower than the current data obtained about 4 yr later. The cumulative and the yearly changes have been $+4.3 \%$ and $+1.2 \%$ per $y r$ for wheezing in the last 12 months and $+2.7 \%$ and $+0.7 \%$ per yr for lifetime asthma, respectively. Rhinoconjunctivitis prevalence in Palermo in 2002 was $11.9 \%$, i.e., much lower than the current result $(20.0 \%)$, yielding a $+8.1 \%$ cumulative and $\mathrm{a}+2.2 \%$ yearly change. Thus, asthma and rhinoconjunctivitis epidemics are still going on in our population sample.

Conversely, eczema prevalence $(5.3 \%)$ was lower than previously reported for adolescents of Southern Italy $(7.4 \%)$ (4). With regard to 2002 Palermo data $(8.6 \%)$, total and yearly changes were $-3.3 \%$ and $-0.9 \%$ per $y r$ : such decrease might be related to climatic changes, as suggested by Suárez-Varela et al. who reported eczema as dependent on meteorological conditions being positively associated with precipitation and humidity and negatively associated with hot climate (15).

No significant gender difference was found in both A and CA prevalence rates, differently from previous observations (16). Indeed, SIDRIA male adolescents (13-14 yr) did not have higher prevalence of A than girls (4).

\section{Evaluation of allergic sensitization}

The use of skin prick testing allowed the objective evaluation of allergic sensitization. Prevalence of positive SPT among adolescents appeared high $(39.2 \%)$, but comparable to the values of $40 \%$ (5) and $49 \%$ (6) previously found in industrialized areas of North Italy. We detected a risk increase for CA depending on the increasing number of sensitizations: when compared to unsensitized adolescents (i.e., $\mathrm{AI}=0$ ), the adjusted OR of having three or more sensitizations $(\mathrm{AI}=3)$ was almost fivefold for CA. Interestingly, in asymptomatic subjects with positive SPT, the sensitization to only one allergen was more frequent than in symptomatic allergic subjects, among which polysensitizations significantly increased. This is in agreement with previous reports indicating that sensitization to inhalant allergens remains a major risk factor for asthma in allergic individuals (17).

The objective evaluation of allergic sensitization also allowed the construction of a double proportional Venn diagram of allergic respiratory diseases showing differences in the prevalence of allergic diseases among subjects with and without positive SPT: in Fig. 1, the large role of allergic sensitization for CA is evident. It is also to point out that the PAR $\%$ value because of allergy was $53.3 \%$ for CA $(19.8 \%$ due a single allergen, dermatophagoides) and that subjects with allergic rhinoconjunctivitis reporting also CA were threefold with respect to non-allergic RC. Thus, as previously demonstrated by Sears et al. in New Zealand boys and girls (18), asthma 
is strongly associated with atopy in adolescents. In another Italian population study, atopy was also associated with asthma and asthma-like symptoms in both sexes (19). Similarly, in the present study, we found that sensitization to indoor perennial allergens was associated with a significantly increased prevalence of CA also in dermatophagoides monosensitized individuals. This could be explained by the increase in markers of airway inflammation found in allergic subjects, in particular those sensitized to indoor perennial allergens (20).

\section{Determinants of allergic respiratory diseases}

Interestingly, environmental factors (ETS, mold/ dampness, and traffic exposures) appear to play a significant role in $\mathrm{CA}$, in agreement with a previous study on Italian children demonstrating an increased risk of asthma and rhinoconjunctivitis for exposure to home dampness (21) and with a recent report from Xepapadaki et al., remarking the effect of ETS on wheeze and on doctor diagnosed asthma in Greek pre-school children (22). Moreover, we found a significantly increased risk of allergic sensitizations to indoor allergens among subjects reporting traffic exposure: we are aware of the risk that, without a validation by Geographical Information System, self-reported vehicular traffic exposure around the house of residence could be affect by recall bias. Nevertheless, our findings are in total agreement with those recently obtained by Annesi-Maesano et al. (23) in French children and also by Han et al. in children of Southern Taiwan (24), suggesting an interaction between perceived traffic-related pollution and allergens possibly producing an enhanced allergic response in children. Moreover, Cesaroni et al. found that self-reported traffic density in area of residence was clearly correlated to particulate matter emission and estimated nitrogen dioxide, strongly suggesting that individual perception of traffic intensity in the area of residence correlates to more objective indices of exposure (25).

In our study, the presence of RC determined a significant increase of the risk for CA $(\mathrm{OR}=3.48)$ and the relevant $\mathrm{PAR} \%$ (i.e., the reduction in CA prevalence that would be observed if the population were entirely unaffected by RC) accounted for $32.2 \%$. This finding is in agreement with previous reports demonstrating that rhinitis is an independent risk factor for asthma as stated in ARIA Guidelines (26) and underscores the need for the physician to always perform a comprehensive assessment of the airways and to consider of evaluating lower airways in patients with rhinitis. The concurrent association of $\mathrm{RC}$ with $\mathrm{CA}$ confirms that allergic sensitization is the prominent risk factor for asthma onset.

We found a higher prevalence of RC among girls, according to the SIDRIA2 Study (4) and to a more recent epidemiological survey performed on Italian schoolchildren (27). RC alone was not strongly linked to allergic sensitization in our sample: (i) only $44.6 \%$ of RC had a positive skin test (close to the prevalence in the total population sample) compared to $77.8 \%$ of subjects with both $\mathrm{CA}$ and $\mathrm{RC}$; (ii) the distribution of Dermatophagoides and Parietaria sensitizations was not far from that in the whole sample; (iii) atopic index was lower with respect to children with CA; and (iv) the increase in RC prevalence with increasing AI (from $16.3 \%$ to $24.9 \%$ ) was lower than for CA (from $1.8 \%$ to $10.3 \%$ ); the PAR value of allergic sensitization for RC was $16.5 \%$, less than one-third with respect to the PAR for CA. Thus, other determinants than allergic sensitization appear relevant for RC. In fact, while exposure to traffic is a risk factor also for CA, all the investigated environmental factors (mold/dampness, ETS, and exposure to traffic) play a larger role in $\mathrm{RC}$, in agreement with the results of Corbo et al. (28) and with previous studies demonstrating that RC may be linked to ETS (29).

\section{Pulmonary function}

Asthmatic subjects showed lower values of $\mathrm{FEV}_{1}, \mathrm{FEV}_{1} / \mathrm{FVC}$, and $\mathrm{FEF}_{25-75 \%}$, and among subjects with $\mathrm{CA}$, the risk of impaired lung function (i.e., a low $\mathrm{FEV}_{1} / \mathrm{FVC}$ ) was threefold with respect to asymptomatic children. Performing spirometric measures made possible to identify subjects with impaired lung function also among subjects not reporting CA, strongly suggesting the effect of environmental factors in the absence of any history of respiratory disease. In particular, we found that self-reported residential traffic-related air pollution exposure was associated with impaired lung function, as recently shown by Oftedal et al. (30) and by Rosenlund et al. (31) through objective estimates of outdoor air pollution exposure. Indeed, our results are in agreement with the very recently published results of SIDRIA2 Study, which have linked reported traffic exposure to questionnaire-variables such as asthma and productive cough (32). Conversely, according to Jaén et al. (33), atopy per se was never associated with poorer pulmonary function, as defined on $\mathrm{FEV}_{1} / \mathrm{FVC} \%$ below 
the 5th percentile of its normal distribution. We also made a sensitive analysis by using a milder definition for impaired lung function based on $\mathrm{FEF}_{25-75 \%}$ (cut-off of $60 \%$ of predicted for boys and $62 \%$ for girls). Also in this case, no significant independent effect of atopy was found on lung function.

Our study indicates that (i) prevalence rates of allergic sensitization, asthma, and rhinoconjunctivitis are still increasing and Venn diagram provides additional information about the prevalence of the coexistent allergic diseases in adolescents; (ii) the role of allergen sensitization (and perennial indoor allergens in particular) is more important for $\mathrm{CA}$ than $\mathrm{RC}$; and (iii) avoiding exposures to measured environmental risk factors would prevent $39 \%$ of current asthma and $34 \%$ of rhinoconjunctivitis. Both presence of current asthma and self-reported traffic exposure in the zone of residence are associated with a poorer lung function in our population sample.

\section{Eczema}

As previously reported, female gender was associated to E (27), while both RC and CA were significant risk factors for $\mathrm{E}$. Moreover, CA and RC accounted for about $30 \%$ of PAR for E. Thus, the concurrent association of CA, RC, and E may be viewed in the context of the atopic March theory, confirming that allergic sensitization is the prominent risk factor for asthma onset (34).

\section{Conclusion}

Public health policies aimed at the abatement of these avoidable environmental risk factors (exposures to mold/dampness, ETS, and traffic) could obtain a significant reduction of the worldwide increasing burden that $\mathrm{CA}$ and $\mathrm{RC}$ cases determine to governments, health care systems, families, and patients.

\section{Acknowledgements}

The present research was fully supported by a grant from Regional Agency for Environment Protection (ARPA Sicilia) [DDG No. 303/2005]. We are grateful to $\mathrm{Mr}$ Paolo Amatuzzo, Mrs Francesca D'Aniello, Mrs Angelica Magliocco, and Mrs Maria Antonietta Tripoli for their technical assistance. We also thank all the school staff, children, and parents who made possible the study.

\section{References}

1. Asher Mi, Montefort S, Büörkstén B, et al.; ISAAC Phase Three Study Group. Worldwide time trends in the prevalence of symptoms of asthma, allergic rhinoconjunctivitis, and eczema in childhood: ISAAC Phases
One and Three repeat multicountry cross-sectional surveys. Lancet 2006: 368: 733-43.

2. Buörkstén B, Clayton T, Ellwood P, Stewart A, Strachan D, ISAAC Phase III Study Group. Worldwide time trends for symptoms of rhinitis and conjunctivitis: Phase III of the International Study of Asthma and Allergies in Childhood. Pediatr Allergy Immunol 2008: 19: 110-24.

3. Galassi C, De Sario M, Biggeri A, et al. Changes in prevalence of asthma and allergies among children and adolescents in Italy: 1994-2002. Pediatrics 2006: 117: 34-42.

4. Sestini P, De Sario M, Bugiani M, et al.; SidRia-2 Collaborative Group. Frequency of asthma and allergies in Italian children and adolescents: results from SIDRIA-2. Epidemiol Prev 2005: 29 (Suppl 2): 24-31.

5. Crimi P, Minale P, Tazzer C, Zanardi S, Ciprandi G. Asthma and rhinitis in schoolchildren: the impact of allergic sensitization to aeroallergens. J Investig Allergol Clin Immunol 2001: 11: 103-6.

6. Duse M, Donato F, Porteri V, et al. High prevalence of atopy, but not of asthma, among children in an industrialized area in North Italy: the role of familial and environmental factors - a population-based study. Pediatr Allergy Immunol 2007: 18: 201-8.

7. Smith He, Hogger C, Lallemant C, Crook D, Frew AJ. Is structured allergy history sufficient when assessing patients with asthma and rhinitis in general practice? J Allergy Clin Immunol 2009: 123: 646-50.

8. The International Study of Asthma, Allergies in Childhood (ISAAC) Steering Committee. Worldwide variation in prevalence of symptoms of asthma, allergic rhinoconjunctivitis, and atopic eczema: ISAAC. Lancet 1998: 351: 1225-32.

9. Asher Mi, Keil U, Anderson HR, et al. Williams. International Study of Asthma and Allergies in Childhood (ISAAC): rationale and methods. Eur Respir J 1995: 8: 483-91.

10. Position PAPer: Allergen Standardization, SKin TESTS. The European Academy of Allergology and Clinical Immunology. Allergy 1993: 48: 48-82.

11. Miller MR, Hankinson J, Brusasco V, et al.; ATS/ ERS TASK FORCE. Standardisation of spirometry. Eur Respir J 2005: 26: 319-38.

12. Pistelli F, Bottai M, Carrozzi L, et al. Reference equations for spirometry from a general population sample in central Italy. Respir Med 2007: 101: 81425.

13. Viegi G, Matteelli G, Angino A, et al. The proportional Venn diagram of obstructive lung disease in the Italian general population. Chest 2004: 126: 1093 101.

14. Balmes J, Becklake M, Blanc P, et al.; Environmental, Occupational Health Assembly, American Thoracic Society. American Thoracic Society Statement: occupational contribution to the burden of airway disease. Am J Respir Crit Care Med 2003: 167: 787-97.

15. Suárez-Varela MM, García-Marcos Alvarez L, KogAN MD, et al. Climate and prevalence of atopic eczema in 6- to 7-year-old school children in Spain. ISAAC phase III. Int J Biometeorol 2008: 52: 833-40.

16. Almovist C, Worm M, Leynaert B; working Group OF GA2LEN WP 2.5 GENDER. Impact of gender on 


\section{Cibella et al.}

asthma in childhood and adolescence: a GA2LEN review. Allergy 2008: 63: 47-57.

17. Custovic A, Simpson A. Environmental allergen exposure, sensitisation and asthma: from whole populations to individuals at risk. Thorax 2004: 59: 825-7.

18. Sears Mr, Burrows B, Flannery EM, Herbison GP, Holdaway MD. Atopy in childhood. I. Gender and allergen related risks for development of hay fever and asthma. Clin Exp Allergy 1993: 23: 941-8.

19. Baldacci S, Modena P, Carrozzi L, et al. Skin prick test reactivity to common aeroallergens in relation to total IgE, respiratory symptoms, and smoking in a general population sample of northern Italy. Allergy 1996: 51: 149-56.

20. Cibella F, Cuttitta G, La Grutta S, Passalacqua G, VIEGI G. Factors influencing exhaled nitric oxide in Italian schoolchildren. Ann Allergy Asthma Immunol 2008: 101: 407-12.

21. Simoni M, Lombardi E, Berti G, et al.; SIDRIA-2 Collaborative Group. Mould/dampness exposure at home is associated with respiratory disorders in Italian children and adolescents: the SIDRIA-2 Study. Occup Environ Med 2005: 62: 616-22.

22. Xepapadaki P, Manios Y, Liarigkovinos $\mathrm{T}$, et al. Association of passive exposure of pregnant women to environmental tobacco smoke with asthma symptoms in children. Pediatr Allergy Immunol 2009: 20: 423-9.

23. Annesi-Maesano I, Moreau D, Caillaud D, et al. Residential proximity fine particles related to allergic sensitisation and asthma in primary school children. Respir Med 2007: 101: 1721-9.

24. Han YY, Lee YL, Guo YL. Indoor environmental risk factors and seasonal variation of childhood asthma. Pediatr Allergy Immunol 2009: 20: 748-56.

25. Cesaroni G, Badaloni C, Porta D, Forastiere F, Perucci CA. Comparison between various indices of exposure to traffic-related air pollution and their impact on respiratory health in adults. Occup Environ Med 2008: 65: 683-90.
26. Bousquet J, Khaltaev N, Cruz AA, et al. Allergic Rhinitis and its Impact on Asthma (ARIA) 2008 Update (in collaboration with the World Health Organization, GA2LEN and AllerGen). Allergy 2008: 63: S8-160.

27. Brescianini S, Brunetto B, Iacovacci P, et al. Prevalence of self-perceived allergic diseases and risk factors in Italian adolescents. Pediatr Allergy Immunol 2009: 20: $578-84$.

28. Corbo GM, Forastiere F, Dell'Orco V, et al. Effects of environment on atopic status and respiratory disorders in children. J Allergy Clin Immunol 1993: 92: 61623 .

29. Simoni M, Baldacci S, Puntoni R, et al. Respiratory symptoms/diseases and environmental tobacco smoke (ETS) in never smoker Italian women. Respir Med 2007: 101: 531-8.

30. Oftedal B, Brunekreef B, Nystad W, Madsen C, Walker SE, Nafstad P. Residential outdoor air pollution and lung function in schoolchildren. Epidemiology 2008: 19: 129-37.

31. Rosenlund M, Forastiere F, Porta D, De Sario M, BADAloni C, PERucCI CA. Traffic-related air pollution in relation to respiratory symptoms, allergic sensitisation and lung function in school children. Thorax 2009: 64: 573-80.

32. Migliore E, Berti G, Galassi C, et al., Ciccone G; SIDRIA-2 Collaborative Group Respiratory symptoms in children living near busy roads and their relationship to vehicular traffic: results of an Italian multicenter study (SIDRIA 2). Environ Health 2009: 8: 27.

33. JaÉn A, Sunyer J, Basagaña X, et al.; European Community Respiratory Health Survey. Specific sensitization to common allergens and pulmonary function in the European Community Respiratory Health Survey. Clin Exp Allergy 2002: 32: 1713-9.

34. Spergel JM. "Atopic March: link to upper airways". Curr Opin Allergy Clin Immunol 2005: 5: 17-21. 